\title{
Salmonella Outer Membrane Vesicles contain tRNA Fragments (tRFs) that Inhibit Bacteriophage P22 infection
}

Dominika Houserova1, Yulong Huang1, Mohan V. Kasukurthi², Brianna C. Watters ${ }^{1,3}$, Fiza F. Khan ${ }^{1}$, Raj V. Mehta $^{1}$, Neil Y. Chaudhary ${ }^{1}$, Justin T. Roberts ${ }^{1,4}$, Jeffrey D. DeMeis ${ }^{1}$, Trevor K. Hobbs ${ }^{1}$, Kanesha R. Ghee ${ }^{1,3}$, Cameron H. Mclnnis ${ }^{1,3}$, Nolan P. Johns ${ }^{1,3}$, Abrianna J. Kegler ${ }^{1,3}$, Alexander B. Coley ${ }^{1}$, Cana L. Brown ${ }^{1}$, Jenny L. Hewes ${ }^{1}$, Marie M. McElyea ${ }^{1}$, Monica N. Reeves ${ }^{1,3}$, Tuan M. Tran ${ }^{3}$, Natalie R. Bauer ${ }^{1}$, Jingshan Huang ${ }^{1,2}$, Jonathon P. Audia ${ }^{5}$, John W. Foster ${ }^{5}$, and Glen M. Borchert ${ }^{1,3, *}$

${ }^{1}$ Department of Pharmacology, University of South Alabama, Mobile, AL, 36688, USA

${ }^{2}$ School of Computing, University of South Alabama, Mobile, AL, 36688, USA

${ }^{3}$ Department of Biology, University of South Alabama, Mobile, AL, 36688, USA

${ }^{4}$ Department of Biochemistry and Molecular Genetics, University of Colorado School of Medicine, Aurora, CO, 80045, USA

${ }^{5}$ Department of Microbiology and Immunology, University of South Alabama, Mobile, AL, 36688, USA

* To whom correspondence should be addressed: Tel: +1 251461 1367; Email: borchert@southalabama.edu 


\section{ABSTRACT}

Salmonella Outer Membrane Vesicles (OMVs) were recently shown to inhibit P22 bacteriophage infection. Furthermore, despite there being several published reports now independently describing (1) the marked prevalence of tRFs within secreted vesicle transcriptomes and (2) roles for specific tRFs in facilitating/inhibiting viral replication, there have been no examinations of the effects of vesicle-secreted tRFs on viral infection reported to date. Notably, while specific tRFs have been reported in a number of bacteria, the tRFs expressed by salmonellae have not been previously characterized. As such, we recently screened small RNA-seq datasets for the presence of recurrent, specifically excised tRFs and identified 31 recurrent, relatively abundant tRFs expressed by Salmonella enterica serovar Typhimurium (SL1344). What's more, we find S. Typhimurium OMVs contain significant levels of tRFs highly complementary to known Salmonella enterica-infecting bacteriophage with 17 of 31 tRFs bearing marked complementarity to at least one known Salmonella entericainfecting phage (averaging 97.4\% complementarity over $22.9 \mathrm{nt}$ ). Most notably, tRNA-Thr-CGT-1-1, 44-73, bears $100 \%$ sequence complementary over its entire $30 \mathrm{nt}$ length to 29 distinct, annotated Salmonella enterica-infecting bacteriophage including P22. Importantly, we find inhibiting this tRF in secreted OMVs improves P22 infectivity in a dose dependent manner whereas raising OMV tRF levels conversely inhibits P22 infectivity. Furthermore, we find P22 phage pre-incubation with OMVs isolated from naïve, control SL1344 S. Typhimurium, successfully rescues the ability of $S$. Typhimurium transformed with a specific tRNA-Thr-CGT-11, 44-73 tRF inhibitor to defend against P22. Collectively, these experiments confirm tRFs secreted in $S$. Typhimurium OMVs are directly involved with and required for the ability of OMVs to defend against bacteriophage predation. As we find the majority of OMV tRFs are highly complementary to an array of known Salmonella enterica-infecting bacteriophage, we suggest OMV tRFs may primarily function as a broadly acting, previously uncharacterized innate antiviral defense. 


\section{INTRODUCTION}

Developmentally regulated cleavage of tRNAs was initially reported in Streptomyces coelicolor in $2008^{1}$. In 2009, however, tRNA-derived RNA fragments (tRFs) of 20 to $30 \mathrm{nt}$ in length were first recognized as a class of functional small non-coding RNAs by a number of laboratories ${ }^{2-4}$. Since these initial reports, tRFs have been identified in all domains of life ${ }^{5}$. Despite this, how tRFs are generated and the functional roles of the majority of tRFs remain unclear although tRFs have been suggested to have initially arisen as a part of an ancient viral defense $^{6}$. Supporting this concept, human endogenous retrovirus transposition rates can be limited by host tRF expression7, and specific tRFs are induced by viral infections (e.g., by RSV ${ }^{8,9}$ ). Notably, increasing titers of HIV have been shown to trigger the production of lysine tRFs that inhibit HIV, and T cells infected with human T-cell leukemia virus type 1 (HTLV-1) similarly upregulate the production of proline tRFs targeting this virus ${ }^{10}$.

Together, these findings suggest that tRFs may constitute an uncharacterized component of the innate antiviral response.

Notably, tRFs have recently been found to be significantly enriched in Outer Membrane Vesicles (OMVs) ${ }^{11}$. OMVs are membrane-encapsulated spherical structures $\sim 50$ to $250 \mathrm{~nm}$ in diameter derived from Gramnegative bacteria cell envelopes ${ }^{12}$. OMVs are primarily generated by outer membrane blebbing but contain proteins, DNA, and RNAs at concentrations distinct from that of the intracellular complement ${ }^{11,12}$. OMVs have been associated with a number of different cellular functions including detoxification, pathogenicity, intercellular communication, and resistance to stressors ${ }^{13}$. Importantly, in 2015, Ghosal et al. found the majority of RNA contained within Escherichia coli OMVs has a length < $60 \mathrm{nt}$ with an enrichment between 15 and 40 nts, and that $E$. coli OMV RNA sequencing reads primarily correspond to tRFs ${ }^{10}$. More recently, Koeppen et al. ${ }^{14}$ likewise found tRFs levels significantly higher in RNA isolated from Pseudomonas aeruginosa OMV than in intracellular RNA suggesting tRFs are actively enriched in OMVs prior to secretion. Interestingly, despite tRNAs and tRFs typically constituting only $\sim 15 \%$ and $2 \%$ of normal intracellular small RNA populations respectively, tRFs have now been reported by several groups as being similarly abundant (representing $>20 \%$ of RNA compositions) in secreted exosomal vesicles isolated from human saliva ${ }^{15}$, plasma ${ }^{16}$, semen ${ }^{17}$, mast cells ${ }^{17}$, mesenchymal stem cells ${ }^{18}$, and neurons ${ }^{19}$.

In summary, despite there being several published reports now independently describing (1) roles for specific tRFs in facilitating/inhibiting viral replication ${ }^{3,8-10,20}$, (2) the marked prevalence of tRFs within secreted vesicles (both exosomes and OMVs) ${ }^{11,14-18}$, and (3) the ability of OMVs to inhibit phage infection of several bacterial species (e.g., E. coli ${ }^{21}$, Prochlorococcus marinus ${ }^{22}$, Shigella flexneri ${ }^{23}$, Salmonella enterica ${ }^{24}$, and Vibrio cholerae $^{25}$ ) there have been no examinations of the effects of vesicle-secreted tRFs on viral infection reported to date. Therefore, in light of a study in 2020 that conclusively demonstrated the ability of Salmonella enterica serovar Typhimurium OMVs to defend against bacteriophage $\mathrm{P}^{22^{24}}$, we recently elected to define the full repertoire of Salmonella enterica serovar Typhimurium tRFs and explore their potential involvement in combating bacteriophage predation. 


\section{RESULTS}

\section{Salmonella enterica serovar Typhimurium tRFs}

Specific tRFs have been reported in a number of bacteria ${ }^{11,26}$. To date, however, the tRFs expressed by $S$. Typhimurium have not been characterized. As such, we recently screened 12 preexisting small RNA seq datasets: six generated by our group ${ }^{27}$ and six by others ${ }^{28,29}$ for the presence of recurrent, specifically excised tRFs. Through employing a novel RNA-seq analysis platform designed to annotate fragments excised from longer noncoding RNAs, (SURFr) ${ }^{30,31}$, we have successfully identified 31 recurrent, relatively abundant tRFs expressed by $S$. Typhimurium. These tRFs average $26.7 \mathrm{nt}$ in length ranging between $19 \mathrm{nt}$ for the shortest (tRNA-Pro-TGG-1-1, 49-75) and $38 \mathrm{nt}$ for the longest (tRNA-fMet-CAT-2-1, 33-70). All but four tRFs were found to be expressed under multiple conditions, and the median maximum tRF expression for all tRFs was 1,799 RPM with a mean of 4,333 RPM (Table 1). Notably, we find tRFs are similarly abundant in E. coli, $V$. cholera, Staphylococcus aureus, and P.aeruginosa small RNA transcriptomes (Supplemental Tables 1-4).

\section{tRNA-Thr-CGT-1-1, 44-73}

In order to confirm the identities of SURFr-called tRFs, we selected tRNA-Thr-CGT-1-1, 44-73 for experimental validation. SURFr reported a $30 \mathrm{nt}$ tRF specifically excised from the 3' end of tRNA-Thr-CGT-1-1 at positions 44-73 (Figure 1 A-C). While we find little expression of this tRF during exponential growth, we find it is robustly expressed (avg. 1,025 RPM) during Carbon starvation (Table 1). Importantly, subsequent qRT-PCRs confirm the expression of this specific tRF in response to Carbon starvation (Figure 1D).

\section{S. Typhimurium tRFs are highly complementary to bacteriophage}

As tRNA fragments were first observed during bacterial phage infections ${ }^{32}$, we next evaluated the potential for these tRFs to interact with bacteriophage through direct basepairing. Strikingly, we found 17 of 31 SURFrcalled $S$. Typhimurium tRFs bear marked complementarity to at least one known $S$. Typhimurium phage with an average sequence alignment of $97.4 \%$ complementarity over $22.9 \mathrm{nt}$. Of note, only two of these seventeen tRFs were identified as being complementary to a single bacteriophage. The other fifteen tRFs averaged significant complementarities to multiple, distinct phage (avg. 7.1) with tRNA-Leu-CAA-2-1, 39-60 significantly aligning to 24 phage, tRNA-Lys-TTT-2-1, 51-75 significantly aligning to 32 phage, and tRNA-Thr-CGT-1-1, 4473 significantly aligning to 29 phage (Supplemental Table 5). In all, significant complementarities to 107 of 475 Salmonella enterica-infecting bacteriophage genomes available at the bacterial bioinformatics PathoSystems Resource Integration Center (PATRIC) $)^{33}$ were identified. Perhaps most notably, the tRF detailed in Figure 1, tRNA-Thr-CGT-1-1, 44-73, was found to be 100\% complementary over its entire $30 \mathrm{nt}$ length to 29 distinct annotated Salmonella enterica-infecting bacteriophage genomes (Supplemental Table 6).

\section{tRNA-Thr-CGT-1-1, 44-73 tRF sequestration improves P22 infectivity}

In light of the striking complementarities between Salmonella enterica-infecting phage and SURFr-identified tRFs, we next asked if tRNA-Thr-CGT-1-1, 44-73 tRF expression was inhibitory to bacteriophage infection. We selected P22 for our analyses as tRNA-Thr-CGT-1-1, 44-73 tRF bears 100\% sequence complementary over its entire $30 \mathrm{nt}$ length to P22 bacteriophage (Figure 2A), and since P22 is extremely well characterized and has long been an important tool for investigating salmonella genetics ${ }^{34}$. We began by determining the effects of sequestering tRFs intracellularly. To achieve this, we preemptively transformed $S$. Typhimurium with antagomiR oligonucleotides perfectly complementary to tRNA-Thr-CGT-1-1, 44-73 tRF (Anti), identical to this tRF (Pos), or scrambled controls then assessed P22 infectivity via plating efficiency. We find preemptive transformation of $S$. Typhimurium with an antagomiR oligonucleotide designed to specifically bind and inhibit tRNA-Thr-CGT-1-1, 44-73 tRF (Anti) improved P22 infectivity in a dose dependent manner with antagomiR transformation improving P22 infectivity by $\sim 60 \%$ at a $10^{-3} \mathrm{P} 22$ dilution and nearly $450 \%$ at a $10^{-4}$ dilution

(Figure 2B,C). In contrast, transformation with control antagomiRs with sequences either unrelated (scrambled) or identical to this tRF (Pos) did not significantly affect infectivity. Importantly, plating efficiency was assessed in unstarved cells as we find relatively limited expression of this tRF during growth in carboncontaining media (Table 1). 


\section{S. Typhimurium OMV inhibition of P22 requires tRNA-Thr-CGT-1-1, 44-73 tRF}

S. Typhimurium OMVs were recently reported to inhibit bacteriophage P22 infection ${ }^{24}$. Therefore, in light of having found that tRNA-Thr-CGT-1-1, 44-73 tRF intracellular sequestration improves P22 infectivity, we next explored the potential role of tRNA-Thr-CGT-1-1, 44-73 tRF in OMV-mediated P22 restriction. SURFr ${ }^{30,31}$ analysis of available $S$. Typhimurium OMV RNA-sequencing data (SRR6843039) ${ }^{35}$ and qRT-PCR of our own OMV RNA isolates both confirm the presence of tRNA-Thr-CGT-1-1, 44-73 tRF within S. Typhimurium OMVs. What's more, we find tRNA-Thr-CGT-1-1, 44-73 tRF levels are $~ 3.5 x$ higher in OMV RNA isolates than in total cellular RNA (Figure 3A). Notably, the average diameter of our isolated vesicles $(119.1 \mathrm{~nm})$ strongly agrees with OMV identity ${ }^{11,12}$ (Figure 3B), and fluorescence-activated cell sorting following Texas Red labeled antagomiR internalization confirms OMV isolates are readily transfectable (Figure $3 \mathbf{C}$ ).

As such, we proceeded by preincubating P22 phage with OMVs transfected with antagomiR oligonucleotides perfectly complementary to tRNA-Thr-CGT-1-1, 44-73 tRF (Anti), identical to this tRF (Pos), or scrambled control then assessed the effects of preincubation with OMVs on P22 infectivity by measuring plating efficiency in naïve, untransformed $S$. Typhimurium. Excitingly, we find P22 phage pre-incubation with OMVs containing the antagomiR shown to inhibit tRNA-Thr-CGT-1-1, 44-73 tRF and improve P22 infectivity in a dose dependent manner following transformation (Figure 2) similarly improved P22 infectivity of naïve control $S$. Typhimurium by $\sim 250 \%$ at a $10^{-4}$ P22 dilution whereas preincubation with OMVs containing elevated tRNA-Thr-CGT-1-1, 4473 tRF levels (Pos) conversely inhibited P22 infectivity by $>75 \%$ (Figure 3D,E) as compared to controls. Importantly, we find P22 phage pre-incubation with OMVs isolated from naïve control $S$. Typhimurium successfully rescues the ability of $S$. Typhimurium transformed with the tRNA-Thr-CGT-1-1, 44-73 tRF antagomiR to defend against P22 which strongly suggests OMV tRFs are primarily responsible for phage inhibition (Figure 3F). Finally, infectivity was not significantly altered following P22 pre-incubation with OMVs transfected with control antagomiRs as compared to infectivity following pre-incubation with naïve OMVs. 


\section{DISCUSSION}

For decades, it was widely believed that the sole role of tRNAs was to convert the information encoded on mRNAs into amino acid sequence. Despite the existence of tRNA-derived fragments (tRFs) being known since the 1990s, until quite recently they have generally been disregarded as degradation products. Notably, pieces of tRNAs were first observed during phage infections of bacteria ${ }^{1}$, and in humans, endogenous retrovirus transposition rates can be limited by host tRF expression and specific tRFs are induced by viral infection ${ }^{3,8-}$ 10,20 . Together, these findings potentially suggest a role for tRFs in innate antiviral defense. However, while specific tRFs have been reported in a number of bacteria, neither (1) the tRFs expressed by salmonellae nor (2) roles for tRFs in combatting bacteriophage have been reported to date.

While specific tRFs have been reported in a number of bacteria, the tRFs expressed by salmonellae have not been previously characterized. As such, we recently screened small RNA-seq datasets for the presence of recurrent, specifically excised tRFs and identified 31 recurrent, relatively abundant tRFs expressed by $S$. Typhimurium. What's more, $S$. Typhimurium OMVs can inhibit P22 bacteriophage infection ${ }^{24}$, and we find $S$. Typhimurium OMVs contain significant levels of tRFs highly complementary to known Salmonella entericainfecting bacteriophage. Most notably, tRNA-Thr-CGT-1-1, 44-73, is 100\% complementary to 29 distinct, annotated Salmonella enterica-infecting bacteriophage including P22, and this tRF is $100 \%$ conserved in E. coli (Supplemental Table 1).Excitingly, we find inhibiting this tRF in secreted OMVs improves P22 infectivity in a dose dependent manner whereas raising OMV tRF levels conversely inhibits P22 infectivity. Furthermore, we find P22 phage pre-incubation with OMVs isolated from naïve, control $S$. Typhimurium, (and therefore containing unaltered, baseline tRF levels) successfully rescues the ability of $S$. Typhimurium preemptively depleted of tRNA-Thr-CGT-1-1, 44-73 tRF to defend against P22. Collectively, these experiments confirm tRFs secreted in $S$. Typhimurium OMVs are directly involved with and required for the ability of OMVs to defend against bacteriophage predation.

In agreement with the proposed role for OMV tRFs in combatting phage infection, the ability of OMVs to inhibit phage infection of several bacterial species (e.g. E. coli ${ }^{21}, P$. marinus ${ }^{22}, S$. flexneri ${ }^{23}$, S. enterica ${ }^{24}$, and $V$. cholera $e^{25}$ ) has now been reported. What's more, in addition to the confirmation that $S$. Typhimurium OMVs contain significant levels of tRFs reported here, tRFs have been reported to be significantly enriched in $E$. coli and $P$. aeruginosa OMVs. In 2015, Ghosal et al. found the majority of RNA contained within E. coli OMVs has a length $<60 \mathrm{nt}$ with an enrichment between 15 and $40 \mathrm{nts}$, and that $E$. coli OMV RNA sequencing reads primarily correspond to tRFs. More recently, Koeppen et al. ${ }^{14}$ likewise found tRFs levels significantly higher in RNA isolated from $P$. aeruginosa OMVs than in intracellular RNA suggesting tRFs are actively enriched in OMVs prior to secretion.

Of note, in 2014, Biller et al. mixed purified Prochlorococcus vesicles with an infective phage (PHM-2) and used electron microscopy to record numerous examples of direct vesicle binding by phage. They found, many vesicle-attached phage had altered capsid staining density and a shortened stalk suggesting that they had injected their DNA into the vesicle. In light of this, they suggested their findings support a decoy model in which the export of vesicles by marine bacteria acts to reduce the likelihood of cellular infection through effectively reducing the number of phage available to infect cells ${ }^{22}$. Of note, our work contradicts elements of this model in that although cells are constantly releasing OMVs, we find the inhibition of specific OMV tRFs can significantly reduce the ability of OMVs to restrict phage infectivity suggesting the requirement for a direct interaction between tRFs and the phage they inhibit.

Also of interest, transfer RNA genes have long been known to represent the preferred chromosomal sites for bacteria prophage integration. Generally, both Gram-negative and Gram-positive prophages integrate into tRNA loci in the proper orientation for the phage attP site to reconstitute the tRNA upon entry ${ }^{36}$. Notably, the primary tRF examined in this work, tRNA-Thr-CGT-1-1, 44-73, bears $100 \%$ sequence complementary over its entire 30 nt length to 29 distinct, annotated Salmonella enterica-infecting bacteriophage including P22 (Table 2), and interestingly, the tRNA locus expressing this tRF also serves as the specific genomic site targeted by P22 for prophage integration ${ }^{37,38}$.

That said, how or if this tRF directly interacts with its complementary sequence at the attP site of the P22 genome remains unclear. Additional studies will clearly be required to determine whether this interaction 
occurs ex vivo and to specifically define the mechanism of tRF-based phage restriction including the extent of tRF sequence complementary necessary to confer regulation. While we found 17 of $31 \mathrm{SURFr}$-called S. Typhimurium tRFs bear marked complementarity to at least one known Salmonella enterica-infecting phage with an average sequence alignment of $97.4 \%$ complementarity over $22.9 \mathrm{nt}$ to date, we have only definitively confirmed the ability of tRNA-Thr-CGT-1-1, 44-73 (which bears 100\% sequence complementary over its entire $30 \mathrm{nt}$ length to P22) to restrict P22 phage infection. More fundamentally, the full repertoire of bacterial tRFs being expressed from salmonellae (and those expressed from virtually all other prokaryotes) as well as the tRFs specifically enriched in OMVs remain significant gaps in knowledge. While the 31 tRFs reported here represent the most comprehensive characterization of $S$. Typhimurium tRFs reported to date, we find the tRFs expressed under the six distinct growth conditions evaluated differ significantly suggesting further tRFs expressed during specific conditions and/or challenges not examined in the current study will likely be described. Similarly, we suggest the tRFs we identify in E. coli (54 tRFs from 82 SRR files), V. cholera (20 tRFs from 10 SRR files), $S$. aureus (31 tRFs from 7 SRR files), and $P$. aeruginosa (48 tRFs from 9 SRR files) small RNA transcriptomes (Supplemental Tables 1-4 respectively) likely also represent significant, but incomplete, tRF catalogs.

Finally of note, tRFs unquestionably participate in more than viral defense. In eukaryotes, an array of regulatory roles for tRFs have been reported involving: transcription, translation, apoptosis, cellular proliferation / differentiation, RNAi, intercellular communication, epigenetics, retrotransposon restriction, etc ${ }^{39}$. While several bacterial tRF characterizations have also been reported ${ }^{40-42}$, to date, the functions tRFs serve in prokaryotes are far less well described. Notably, during alkaline stress, Haloferax volcanii has been shown to express a 5' tRF that binds its small ribosomal subunit to interfere with mRNA loading and universally downregulate protein expression ${ }^{43}$. Also of note, bacterial tRFs have been reported to be involved in interspecies communication. Rhizobial tRFs were recently shown to be absorbed by symbiotic hosts and silence the expression of host genes through interacting with their RNA interference machinery ${ }^{44}$.

The work presented here clearly demonstrates that tRFs secreted in S. Typhimurium OMVs are directly involved with and required for the ability of OMVs to defend against bacteriophage predation. As we find the majority of OMV tRFs are highly complementary to an array of known Salmonella enterica-infecting bacteriophage, we speculate that OMV tRFs may primarily function as a broadly acting, previously uncharacterized ancient antiviral defense. Finally, as several published reports have now independently described (1) the marked prevalence of tRFs within exosomal transcriptomes ${ }^{11,14-18}$ and (2) roles for specific human tRFs in inhibiting viral replication ${ }^{3,8-10,20}$, it is tempting to also speculate that vesicle-secreted tRFs may similarly function as broad-spectrum antivirals in eukaryotes. 


\section{METHODS}

Unless stated otherwise all chemicals and kits were purchased from ThermoFisher. Salmonella enterica serovars Typhimurium strains (SL1344 and UK1) and aliquot of P22 HT105/1-int bacteriophage were provided by Dr. John Foster.

\section{SURFr tRF annotation and identification of phage complementarities}

SRA IDs corresponding to bacterial small RNA-seq datasets were obtained from the NCBI SRA database ${ }^{45}$ and entered directly into SURFr, a real-time NGS data analytic tool to identify and analyze ncRNA-derived RNAs, for analysis after selecting the desired bacterial species ${ }^{30,31}$. Filter was set to "tRNA" only, and all tables, reports, and images downloaded. The SURFr platform is publically available at:

http://salts.soc.southalabama.edu/surfr

Final SURFr-identified tRFs were aligned to all 475 Salmonella enterica-infecting bacteriophage genomes available through the bacterial bioinformatics PathoSystems Resource Integration Center (PATRIC) ${ }^{33}$ funded by the National Institute of Allergy and Infectious Diseases (https://www.patricbrc.org) using BLAST+ (2.2.27). All resulting alignments were filtered by requiring a minimum length of 17 base pairs with $100 \%$ sequence identity or $19+$ bps with an evalue of 0.01 or less.

\section{Cultivation of bacterial cultures}

Cultures of $S$. Typhimurium deprived of carbon source and control non-starved were generated as previously described $^{27}$. Briefly, overnight cultures of SL1344 were inoculated into MOPS minimal media (MS) with either low $\left(0.03 \%\right.$; loC) or high $\left(0.4 \%\right.$; hiC) glucose content ${ }^{46}$. Both cultures were then grown at $37^{\circ} \mathrm{C}$ with aeration/shaking until harvested; Non-starved cultures grown in MS-hiC were collected mid-log phase $(\mathrm{OD} 600=0.4)$ while starved cultures grown in MS-loC were collected at 5 hours and 24 hours after reaching stationary phase to ensure complete depletion of C-source. For viral plaque assays and co-incubation experiments standard, commercially available Lysogeny Broth (LB) was used for all $S$. Typhimurium culturing.

\section{Validation of tRF presence via quantitative RT-PCR}

Small RNA was isolated using mirVana miRNA Isolation Kit according to manufacturer's instructions. Realtime, quantitative PCR was performed to validate presence of tRF-21 in UK1 strain of $S$. Typhimurium and its OMVs using All-in-One miRNA qRT-PCR Kit (GeneCopia). The reactions were performed in triplicate in a 96well plates using $0.2 \mathrm{uM}$ of each custom forward and universal reverse primers provided in the kit and $1.5 \mathrm{ug}$ of total RNA in nuclease-free water. qRT-PCR was conducted on the iQ-5 Real-Time PCR Detection System (Bio-Rad) with following settings: initial polymerase activation and DNA denaturation at $95^{\circ} \mathrm{C}$ for 10 minutes, followed by 40 cycles of $95^{\circ} \mathrm{C}$ for $10 \mathrm{sec}, 60^{\circ} \mathrm{C}$ for $20 \mathrm{sec}, 72^{\circ} \mathrm{C}$ for $15 \mathrm{sec}$. Specificity of amplifications was verified using melting curves. Gene expression was calculated via the Delta-Delta cycle threshold method. qRT-PCR primers are listed in Supplemental Table 7.

\section{P22 bacteriophage propagation}

An overnight culture of P22-susceptible $S$. Typhimurium strain UK1 was used to propagate the bacteriophage by overnight co-incubation at $37^{\circ} \mathrm{C}$ with constant shaking. The next day, bacteria were lysed by vigorous vortexing with 3 drops of chloroform and $100 \%$ ethanol. The phage was then precipitated from the lysate by addition of PEG6000 (final concentration $7 \% \mathrm{w} / \mathrm{v}$ ) and $\mathrm{NaCl}$ (final concentration $0.5 \mathrm{M}$ ). Solution was then incubated for $60 \mathrm{~min}$ at RT and phage was concentrated by centrifugation at $8000 \mathrm{xg}$ for $10 \mathrm{~min}$. Phage pellet was then re-suspended in $100 \mathrm{uL}$ of $1 \mathrm{X}$ PBS and stored at $4^{\circ} \mathrm{C}$.

\section{OMV isolation and validation}

An overnight culture of $S$. Typhimurium strain UK1 was inoculated into standard minimal media that was depleted of iron $\left(0.1 \%\right.$ (NH4)2SO4; $0.9 \% \mathrm{KH} 2 \mathrm{PO} 4,0.2 \%$ glycerol, $0.04 \% \mathrm{MgSO} 4$, with $0.5 \mathrm{ug}$ of $\mathrm{Fe}^{2+}$ per $\mathrm{ml}$ ) and grown until late log/early stationary phase. The culture was then collected and cells and large cellular debris removed by centrifugation (5000xg for 15 mins) and two subsequent filtrations with 0.45 and 0.2 micron 
filters. OMVs were then isolated and concentrated using Pall Minimate Tangenial Flow Filtration system and $100 \mathrm{kDa}$ filter cassette. Concentrated particles were further purified by ultracentrifugation (1hr, 120k x g, $4^{\circ} \mathrm{C}$ ). The presence and quantity of OMVs was determined using ZetaView (Particle Metrix ZetaView system) and $1 \times 10^{6}$ OMVs from each sample were transfected with $1 \mu \mathrm{M}$ scrambled control (scram) or $1 \mu \mathrm{M}$ Texas Redlabeled antagomiR (Anti-Red) (Supplemental Table 7) and stained using green fluorescent $\mathrm{DiOC}_{18}(3)$ membrane dye. Samples were then analyzed and sorted on a Becton Dickinson FACS Aria II Analyzer and Cell Sorter. Transfection efficiency was calculated using number of OMVs positive for both green and red labels.

\section{tRF transformation and delivery via OMVs}

Intracellular tRF transformation: An overnight culture of UK-1 was inoculated 1:100 into fresh LB broth media and allowed to grow until early to mid-log phase $(O D=0.3)$. Once grown, the culture was chilled on ice for 10 minutes and the bacteria subsequently pelleted by centrifugation $\left(3000 \mathrm{X} \mathrm{g}, 10\right.$ minutes, $\left.4^{\circ} \mathrm{C}\right)$. The supernatant was discarded and bacteria re-suspended in sterile, ice-cold $0.1 \mathrm{M} \mathrm{CaCl}_{2}$ solution. The culture was then incubated on ice with shaking for additional 30 minutes. Bacteria were pelleted as before, re-suspended in sterile, ice-cold $15 \%$ glycerol in $0.1 \mathrm{M} \mathrm{CaCl}_{2}$, aliquoted into $50 \mu \mathrm{L}$ aliquots and put on ice. $10 \mu \mathrm{L}$ of $100 \mu \mathrm{M}$ of tRF or control oligo was added to the aliquots and left undisturbed on ice for additional 30 minutes. The transformation was performed by heat shock at a $42^{\circ} \mathrm{C}$ water bath for 30 seconds. After transformation samples were incubated on ice for 2 minutes and subsequently diluted 1:1 in pre-warmed S.O.C media and incubated on a shaker at $37^{\circ} \mathrm{C}$ for 20 minutes. OMV tRF transformation: OMVs were transfected with either tRF mimic (Pos) or inhibitor (Anti) Supplemental Table 7. via electroporation using E. coli Pulser (Bio-Rad). Electroporation was performed under same conditions as previously described ${ }^{47}$. Transformed OMVs were put on ice and used immediately. Viral Plaque Assay and Co-incubation: To perform viral plaque assays, bacterial were grown and transfected with desired oligo as described above. After the last incubation, $10 \mu \mathrm{L}$ of viral lysate dilution was added and samples incubated at $37^{\circ} \mathrm{C}$ for additional 10 minutes. Samples were then transferred to a tube containing Molten Top Agar (1\% Bacto tryptone, 0.5\% Bacto yeast extract, $0.5 \% \mathrm{NaCl}$, $0.4 \%$ technical agar, $0.01 \mathrm{M} \mathrm{CaCl} 2, \mathrm{pH} 7.4$ ), mixed and poured onto prepared LB agar plates. Once solidified, plates were incubated at $37^{\circ} \mathrm{C}$ for $24 \mathrm{hrs}$ before the plaques were counted. For OMV tRF delivery experiments, $S$. Typhimurium were transformed with either tRF or control oligos and allowed to incubate in SOC (Super Optimal broth with Catabolite repression) as before. At the same time, $10 \mu \mathrm{L}$ of viral lysate was added to $50 \mu \mathrm{L}$ aliquots of OMVs- either naïve or transfected with tRF-21 oligo. Solutions were then placed on a shaking incubator (200 rpm) and allowed to incubate for 30 minutes. Transfected cells and OMV/viral solutions were then combined, and co-incubated additional 15 minutes before being plated in Molten Top Agar. Plates were incubated at $37^{\circ} \mathrm{C}$ for $24 \mathrm{hrs}$ and viral plaques were counted. 


\section{DATA AVAILABILITY}

All next-generation small RNA deep-sequencing libraries utilized are publicly available and were obtained from NCBI SRA. SRR Files analyzed: SRR6843039, SRR11688424, SRR2149890, SRR2149854, SRR2149895, SRR2149893, SRR11688421, SRR2149882, SRR11688423, SRR11688422, SRR11688425, SRR2149899, SRR11688420. All other relevant data (e.g. alignment files) are available from the authors upon request.

\section{ACKNOWLEDGEMENTS}

We thank the University of South Alabama College of Medicine Department of Pharmacology for ongoing support. Funding was provided in part by NSF RAPID grant 2030080 (GMB) awarded by Division of Molecular and Cellular Biosciences (with co-funding provided by the NSF EPSCoR program), in part by NIH R01HL133066 (NRB), and in part by the USA COM IGP grant 1828 (GMB). Graduate funding was also provided in part by Alabama Commission on Higher Education ALEPSCoR grants 150380 (JDD). The project used an instrument funded, in part, by the National Science Foundation MRI, grant number CNS-1726069.

\section{COMPETING INTERESTS}

The authors declare no conflict of interest.

\section{AUTHOR CONTRIBUTIONS}

$\mathrm{DH}$ and $\mathrm{GMB}$ had full access to all of the data in the study and take responsibility for the integrity of the data and accuracy of the data analysis. This included study concept and design, experimental design and interpretation, data analysis, drafting of manuscript, critical revision of the manuscript for important intellectual content, and general study supervision. Each additional author contributed directly to the design of specific experiments, data analysis and to overall manuscript editing and approval. 


\section{FIGURE LEGENDS}

Figure 1. tRNA-Thr-CGT-1-1, 44-73. (A) SURFr30,31 "Differential Expression Vector" window depicting each nucleotide within tRNA-Thr-CGT-1-1 and indicating the fragment recurrently identified with a blue rectangle. The $x$-axis represents the position in the ncRNA selected (tRNA-Thr-CGT-1-1), and the y-axis depicts the expression level of the ncRNA at each position. (B) tRNA-Thr-CGT-1-1, 44-73 tRF sequence corresponding to the blue rectangle in "A". (C) Secondary structure of tRNA-Thr-CGT-1-1 with positions 44-73 highlighted in green. Structural prediction generated with $\mathrm{mFold}^{48}$. (D) qRT-PCR confirming the increased expression of tRNA-Thr-CGT-1-1, 44-73 tRF in $S$. Typhimurium during carbon starvation $(n=3)$. Relative expression, \% expression as compared to average Log expression. Log, logarithmic phase. $5 \mathrm{~h}, 5$ hour carbon starved. $24 \mathrm{~h}$, 24 hour carbon starved.

Figure 2. tRNA-Thr-CGT-1-1, 44-73 sequestration enhances P22 infectivity. (A) tRNA-Thr-CGT-1-1, 44-73 tRF alignment with P22 bacteriophage. (B) P22 plaque assay following preemptive transformation of $S$. Typhimurium with an antagomiR oligonucleotide (Anti) designed to specifically bind and inhibit tRNA-Thr-CGT1-1, 44-73 tRF or its reverse complement (Pos). Plaque count was normalized to control: $S$. Typhimurium transfected with scrambled antagomiR oligonucleotide (Scram). Bacteria were transformed (CaCl2 heat shock) with antagomiR or control oligo and allowed to recover then viral lysate was added (at the indicated dilutions), mixed with molten top agar, and poured onto LB agar plates. Once solidified, plates were incubated at $37^{\circ} \mathrm{C}$ for $24 \mathrm{hrs}$ then plaques were enumerated. ( $n=3$, p-values determined by unpaired t-test). (C) Representative P22 $\left(10^{-4}\right.$ dilution) plaque assay.

Figure 3. S. Typhimurium OMV inhibition of P22 requires tRNA-Thr-CGT-1-1, 44-73 tRF. (A) qRT-PCR confirming the expression of tRNA-Thr-CGT-1-1, 44-73 tRF in S. Typhimurium OMV RNA. Relative expression, $\%$ expression as compared to average total cellular RNA expression ( $n=3$, p-value determined by unpaired $t-$ test). Cellular, total cellular RNA isolate. OMV, OMV RNA isolate. (B) $S$. Typhimurium OMVs were harvested then analyzed at a 1:100 dilution on ZetaView. Concentration: 1.3E8 particles / mL. (C) $1 \times 10^{6} \mathrm{OMVs}$ from each sample were transfected with $1 \mu \mathrm{M}$ scrambled control oligo (left) or $1 \mu \mathrm{M}$ Texas Red labeled antagomiR (right) then analyzed by Aria FACS. Dot plots show fluorescent intensities of 10,000 events; maximal acquisition time was $6 \mathrm{sec}$ and sample pressure was < 3. Percentages of gated populations are shown. (D) Plaque Assay (10-4 dilution) following P22 phage pre-incubation with OMVs transfected with $1 \mu \mathrm{M}$ scrambled control (Scram), an antagomiR oligo designed to specifically bind and inhibit tRNA-Thr-CGT-1-1, 44-73 tRF (Anti), or its reverse complement (Pos). ( $n=3, p$-value determined by unpaired t-test). (E) Plaque Assay (10-3 dilution), otherwise as in "D". (F) Plaque assay (10-4 dilution). "S0", S. Typhimurium transformed with Scram antagomiR control / no phage preincubation with OMVs. "S-", S. Typhimurium transformed with Anti antagomiR / no phage preincubation with OMVs. "S-NO", S. Typhimurium transformed with Anti antagomiR / phage preincubated with OMVs transfected with Scram antagomiR control. "S-/V-", S. Typhimurium transformed with Anti antagomiR / phage preincubated with OMVs transfected with Anti antagomiR. "SONV", S. Typhimurium transformed with Scram antagomiR control / phage preincubated with OMVs transfected with Scram antagomiR control. "SO/V-", $S$. Typhimurium transformed with Scram antagomiR control / phage preincubated with OMVs transfected with Anti antagomiR.

\section{TABLE LEGENDS}

Table 1. 31 tRFs expressed in S. Typhimurium SL1344. SURFr-identified tRF precursor positions and excised sequences are shown. OD 0.4, Mid-log phase. OD 2.0, Stationary-phase. SPI2, salmonella pathogenicity island 2 conditions: $(\text { SPI-2 medium, OD600 }=0.3)^{28,29}$. OD $0.3,24 \mathrm{~h}$ and 5 h C-starved from ${ }^{27}$.

\section{SUPPLEMENTAL TABLE LEGENDS}

\section{Supplemental Table 1.54 tRFs expressed in Escherichia coli.}




\section{Supplemental Table 2. 20 tRFs expressed in Vibrio cholera.}

Supplemental Table 3. 31 tRFs expressed in Staphylococcus aureus.

Supplemental Table 4. 48 tRFs expressed in Pseudomonas aeruginosa.

Supplemental Table 5.17 S. Typhimurium tRFs are markedly complementary to bacteriophage sequences. "Annotation" and "Start - End" refer to Ensembl tRNA-excised tRFs identified by SURFr"30,31. Phage Name, correspond to phage genomes in the bacterial bioinformatics PathoSystems Resource Integration Center (PATRIC) ${ }^{33}$.

Supplemental Table 6. tRNA-Thr-CGT-1-1, $44-73$ is $100 \%$ complementary to 29 distinct, annotated Salmonella enterica-infecting bacteriophage genomes. Accn, Common Name, Start and Stop positions all correspond to phage genomes in the bacterial bioinformatics PathoSystems Resource Integration Center $\left(\right.$ PATRIC) ${ }^{33}$.

Supplemental Table 7. Oligonucleotide master list. All oligonucleotides were synthesized by IDT DNA Technologies (Coralville, IA) at $100 \mu \mathrm{M}$ scale and HPLC purified. 


\section{REFERENCES}

1. Haiser HJ, Karginov F V., Hannon GJ, Elliot MA. Developmentally regulated cleavage of tRNAs in the bacterium Streptomyces coelicolor. Nucleic Acids Res. Nucleic Acids Res; 2008 Feb;36(3):732-741. https://pubmed.ncbi.nlm.nih.gov/18084030/ PMID: 18084030

2. Lee YS, Shibata Y, Malhotra A, Dutta A. A novel class of small RNAs: tRNA-derived RNA fragments (tRFs). Genes Dev. 2009;23(22):2639-2649. PMID: 19933153

3. Wang Q, Lee I, Ren J, Ajay SS, Lee YS, Bao X. Identification and functional characterization of tRNAderived RNA fragments (tRFs) in respiratory syncytial virus infection. Mol Ther. 2013 Feb;21(2):368-79. PMID: 23183536

4. Martens-Uzunova ES, Olvedy M, Jenster G. Beyond microRNA--novel RNAs derived from small noncoding RNA and their implication in cancer. Cancer Lett. 2013;340(2):201-211. PMID: 23376637

5. Krishna S, Raghavan S, DasGupta R, Palakodeti D. tRNA-derived fragments (tRFs): establishing their turf in post-transcriptional gene regulation. Cellular and Molecular Life Sciences. Cell Mol Life Sci; 2021. p. 2607-2619. https://pubmed.ncbi.nlm.nih.gov/33388834/ PMID: 33388834

6. Schorn AJ, Martienssen R. Tie-Break: Host and Retrotransposons Play tRNA. Trends in Cell Biology. Trends Cell Biol; 2018. p. 793-806. https://pubmed.ncbi.nlm.nih.gov/29934075/ PMID: 29934075

7. Schorn AJ, Gutbrod MJ, LeBlanc C, Martienssen R. LTR-Retrotransposon Control by tRNA-Derived Small RNAs. Cell. Cell; 2017 Jun 29;170(1):61-71.e11. https://pubmed.ncbi.nlm.nih.gov/28666125/ PMID: 28666125

8. Deng J, Ptashkin RN, Chen Y, Cheng Z, Liu G, Phan T, Deng X, Zhou J, Lee I, Lee YS, Bao X. Respiratory Syncytial Virus Utilizes a tRNA Fragment to Suppress Antiviral Responses Through a Novel Targeting Mechanism. Mol Ther. 2015 Oct;23(10):1622-9. PMID: 26156244

9. Zhou J, Liu S, Chen Y, Fu Y, Silver AJ, Hill MS, Lee I, Lee YS, Bao X. Identification of two novel functional tRNA-derived fragments induced in response to respiratory syncytial virus infection. J Gen Virol. 2017 Jul;98(7):1600-1610. PMID: 28708049

10. Ruggero K, Guffanti A, Corradin A, Sharma VK, De Bellis G, Corti G, Grassi A, Zanovello P, Bronte V, Ciminale V, D'Agostino DM. Small noncoding RNAs in cells transformed by human T-cell leukemia virus type 1: a role for a tRNA fragment as a primer for reverse transcriptase. J Virol. 2014 Apr;88(7):361222. PMID: 24403582

11. Ghosal A, Upadhyaya BB, Fritz J V., Heintz-Buschart A, Desai MS, Yusuf D, Huang D, Baumuratov A, Wang K, Galas D, Wilmes P. The extracellular RNA complement of Escherichia coli. Microbiologyopen. Microbiologyopen; 2015 Apr 1;4(2):252-266. https://pubmed.ncbi.nlm.nih.gov/25611733/ PMID: 25611733

12. Avila-Calderón ED, Ruiz-Palma M del S, Aguilera-Arreola MG, Velázquez-Guadarrama N, Ruiz EA, Gomez-Lunar Z, Witonsky S, Contreras-Rodríguez A. Outer Membrane Vesicles of Gram-Negative Bacteria: An Outlook on Biogenesis. Frontiers in Microbiology. Front Microbiol; 2021. https://pubmed.ncbi.nlm.nih.gov/33746909/ PMID: 33746909

13. Jan AT. Outer Membrane Vesicles (OMVs) of gram-negative bacteria: A perspective update. Front Microbiol. Front Microbiol; 2017 Jun 9;8(JUN). https://pubmed.ncbi.nlm.nih.gov/28649237/ PMID: 28649237

14. Koeppen K, Hampton TH, Jarek M, Scharfe M, Gerber SA, Mielcarz DW, Demers EG, Dolben EL, Hammond JH, Hogan DA, Stanton BA. A Novel Mechanism of Host-Pathogen Interaction through sRNA in Bacterial Outer Membrane Vesicles. PLoS Pathog. PLoS Pathog; 2016 Jun 1;12(6). https://pubmed.ncbi.nlm.nih.gov/27295279/ PMID: 27295279

15. Li F, Kaczor-Urbanowicz KE, Sun J, Majem B, Lo H-C, Kim Y, Koyano K, Rao SL, Kang SY, Kim SM, Kim K-M, Kim S, Chia D, Elashoff D, Grogan TR, Xiao X, Wong DTW. Characterization of Human Salivary Extracellular RNA by Next-generation Sequencing. Clin Chem. 2018 Jul;64(7):1085-1095. 
PMID: 29685897

16. Danielson KM, Rubio R, Abderazzaq F, Das S, Wang YE. High Throughput Sequencing of Extracellular RNA from Human Plasma. Margis R, editor. PLoS One. 2017 Jan;12(1):e0164644. PMID: 28060806

17. Lässer C, Shelke GV, Yeri A, Kim D-K, Crescitelli R, Raimondo S, Sjöstrand M, Gho YS, Van Keuren Jensen K, Lötvall J. Two distinct extracellular RNA signatures released by a single cell type identified by microarray and next-generation sequencing. RNA Biol. 2017 Jan;14(1):58-72. PMID: 27791479

18. Baglio SR, Rooijers K, Koppers-Lalic D, Verweij FJ, Pérez Lanzón M, Zini N, Naaijkens B, Perut F, Niessen HWM, Baldini N, Pegtel DM. Human bone marrow- and adipose-mesenchymal stem cells secrete exosomes enriched in distinctive miRNA and tRNA species. Stem Cell Res Ther. 2015 Jul 1;6(1):127. http://www.ncbi.nlm.nih.gov/pubmed/26129847 PMID: 26129847

19. Bellingham SA, Coleman BM, Hill AF. Small RNA deep sequencing reveals a distinct miRNA signature released in exosomes from prion-infected neuronal cells. Nucleic Acids Res. 2012 Nov;40(21):1093749. PMID: 22965126

20. Selitsky SR, Baran-Gale J, Honda M, Yamane D, Masaki T, Fannin EE, Guerra B, Shirasaki T, Shimakami T, Kaneko S, Lanford RE, Lemon SM, Sethupathy P. Small tRNA-derived RNAs are increased and more abundant than microRNAs in chronic hepatitis B and C. Sci Rep. 2015 Jan;5(1):7675. PMID: 25567797

21. Manning AJ, Kuehn MJ. Contribution of bacterial outer membrane vesicles to innate bacterial defense. BMC Microbiol. BMC Microbiol; 2011;11. https://pubmed.ncbi.nlm.nih.gov/22133164/ PMID: 22133164

22. Biller SJ, Schubotz F, Roggensack SE, Thompson AW, Summons RE, Chisholm SW. Bacterial vesicles in marine ecosystems. Science (80- ). Science; 2014;343(6167):183-186.

https://pubmed.ncbi.nlm.nih.gov/24408433/ PMID: 24408433

23. Parent KN, Erb ML, Cardone G, Nguyen K, Gilcrease EB, Porcek NB, Pogliano J, Baker TS, Casjens SR. OmpA and OmpC are critical host factors for bacteriophage Sf6 entry in Shigella. Mol Microbiol. Mol Microbiol; 2014;92(1):47-60. https://pubmed.ncbi.nlm.nih.gov/24673644/ PMID: 24673644

24. Stephan MS, Broeker NK, Saragliadis A, Roos N, Linke D, Barbirz S. In vitro Analysis of O-AntigenSpecific Bacteriophage P22 Inactivation by Salmonella Outer Membrane Vesicles. Front Microbiol. Front Microbiol; 2020 Sep 24;11. https://pubmed.ncbi.nlm.nih.gov/33072001/ PMID: 33072001

25. Reyes-Robles T, Dillard RS, Cairns LS, Silva-Valenzuela CA, Housman M, Ali A, Wright ER, Camilli A. Vibrio cholerae outer membrane vesicles inhibit bacteriophage infection. J Bacteriol. J Bacteriol; 2018 Aug 1;200(15). https://pubmed.ncbi.nlm.nih.gov/29661863/ PMID: 29661863

26. Babski J, Maier LK, Heyer R, Jaschinski K, Prasse D, Jäger D, Randau L, Schmitz RA, Marchfelder A, Soppa J. Small regulatory RNAs in archaea. RNA Biology. RNA Biol; 2014. https://pubmed.ncbi.nlm.nih.gov/24755959/ PMID: 24755959

27. Amin S V, Roberts JT, Patterson DG, Coley AB, Allred JA, Denner JM, Johnson JP, Mullen GE, O’Neal TK, Smith JT, Cardin SE, Carr HT, Carr SL, Cowart HE, DaCosta DH, Herring BR, King VM, Polska CJ, Ward EE, Wise AA, McAllister KN, Chevalier D, Spector MP, Borchert GM. Novel small RNA (sRNA) landscape of the starvation-stress response transcriptome of Salmonella enterica serovar typhimurium. RNA Biol. 2016;13(3):331-342. PMID: 26853797

28. Westermann AJ, Venturini E, Sellin ME, Förstner KU, Hardt WD, Vogel J. The major RNA-binding protein ProQ impacts virulence gene expression in salmonella enterica serovar typhimurium. MBio. mBio; 2019 Jan 1;10(1). https://pubmed.ncbi.nlm.nih.gov/30602583/ PMID: 30602583

29. Venturini E, Svensson SL, Maaß S, Gelhausen R, Eggenhofer F, Li L, Cain AK, Parkhill J, Becher D, Backofen R, Barquist L, Sharma CM, Westermann AJ, Vogel J. A global data-driven census of Salmonella small proteins and their potential functions in bacterial virulence. microLife. Oxford Academic; 2020 Dec 23;1(1):2. https://academic.oup.com/microlife/article/1/1/uqaa002/5928550

30. Kasukurthi M V, Houserova D, Huang Y, Barchie AA, Roberts JT, Li D, Wu B, Huang J, Borchert GM. 
bioRxiv preprint doi: https://doi.org/10.1101/2021.11.09.467952; this version posted November $9,2021$. The copyright holder for this preprint (which was not certified by peer review) is the author/funder, who has granted bioRxiv a license to display the preprint in perpetuity. It is made available under aCC-BY-NC-ND 4.0 International license.

SALTS-SURFR (sncRNA) And LAGOOn (IncRNA) Transcriptomics Suite. bioRxiv. Cold Spring Harbor Laboratory; 2021 Feb. http://salts.soc.southalabama.edu.

31. Kasukurthi MV, Li S, Borchert GM, Huang J, Zhang D, Housevera M, Huang Y, Tan S, Ma B, Li D, Benton R, Lin J. SURFr: Algorithm for identification and analysis of ncRNA-derived RNAs. Proc - 2019 IEEE Int Conf Bioinforma Biomed BIBM 2019. Institute of Electrical and Electronics Engineers Inc.; 2019. p. 1504-1507.

32. Levitz R, Chapman D, Amitsur M, Green R, Snyder L, Kaufmann G. The optional E. coli prr locus encodes a latent form of phage T4-induced anticodon nuclease. EMBO J. John Wiley \& Sons, Ltd; 1990 May 1;9(5):1383-1389. https://onlinelibrary.wiley.com/doi/full/10.1002/j.1460-2075.1990.tb08253.x PMID: 1691706

33. Davis JJ, Wattam AR, Aziz RK, Brettin T, Butler R, Butler RM, Chlenski P, Conrad N, Dickerman A, Dietrich EM, Gabbard JL, Gerdes S, Guard A, Kenyon RW, MacHi D, Mao C, Murphy-Olson D, Nguyen M, Nordberg EK, Olsen GJ, Olson RD, Overbeek JC, Overbeek R, Parrello B, Pusch GD, Shukla M, Thomas C, Vanoeffelen M, Vonstein V, Warren AS, Xia F, Xie D, Yoo H, Stevens R. The PATRIC Bioinformatics Resource Center: Expanding data and analysis capabilities. Nucleic Acids Res. Nucleic Acids Res; 2020 Jan 1;48(D1):D606-D612. https://pubmed.ncbi.nlm.nih.gov/31667520/ PMID: 31667520

34. Levine M. Replication and lysogeny with phage P22 in Salmonella typhimurium.. Current topics in microbiology and immunology. Curr Top Microbiol Immunol; 1972. p. 135-156.

https://pubmed.ncbi.nlm.nih.gov/4559086/ PMID: 4559086

35. Malabirade A, Habier J, Heintz-Buschart A, May P, Godet J, Halder R, Etheridge A, Galas D, Wilmes P, Fritz J V. The RNA complement of outer membrane vesicles from Salmonella enterica Serovar Typhimurium under distinct culture conditions. Front Microbiol. Front Microbiol; 2018 Aug 30;9(AUG). https://pubmed.ncbi.nlm.nih.gov/30214435/ PMID: 30214435

36. Canchaya C, Fournous G, Brüssow H. The impact of prophages on bacterial chromosomes. Molecular Microbiology. Mol Microbiol; 2004. p. 9-18. https://pubmed.ncbi.nlm.nih.gov/15225299/ PMID: 15225299

37. Lindsey DF, Martinez C, Walker JR. Physical map location of the Escherichia coli attachment site for the P22 prophage (attP22). Journal of Bacteriology. J Bacteriol; 1992. p. 3834-3835.

https://pubmed.ncbi.nlm.nih.gov/1534329/ PMID: 1534329

38. Campbell A. Prophage insertion sites. Research in Microbiology. Res Microbiol; 2003. p. 277-282. https://pubmed.ncbi.nlm.nih.gov/12798232/ PMID: 12798232

39. Cao J, Cowan DB, Wang DZ. tRNA-Derived Small RNAs and Their Potential Roles in Cardiac Hypertrophy. Frontiers in Pharmacology. Front Pharmacol; 2020. https://pubmed.ncbi.nlm.nih.gov/33041815/ PMID: 33041815

40. Kumar P, Mudunuri SB, Anaya J, Dutta A. tRFdb: A database for transfer RNA fragments. Nucleic Acids Res. Nucleic Acids Res; 2015 Jan 28;43(D1):D141-D145. https://pubmed.ncbi.nlm.nih.gov/25392422/ PMID: 25392422

41. Liu T, Zhang K, Xu S, Wang Z, Fu H, Tian B, Zheng X, Li W. Detecting RNA-RNA interactions in E. coli using a modified CLASH method. BMC Genomics. BMC Genomics; 2017 May 3;18(1). https://pubmed.ncbi.nlm.nih.gov/28468647/ PMID: 28468647

42. Kang SM, Choi JW, Lee Y, Hong SH, Lee HJ. Identification of microRNA-Size, Small RNAs in escherichia coli. Curr Microbiol. Curr Microbiol; 2013 Nov;67(5):609-613. https://pubmed.ncbi.nlm.nih.gov/23783561/ PMID: 23783561

43. Gebetsberger J, Zywicki M, Künzi A, Polacek N. TRNA-derived fragments target the ribosome and function as regulatory non-coding RNA in Haloferax volcanii. Archaea. Archaea; 2012;2012. https://pubmed.ncbi.nlm.nih.gov/23326205/ PMID: 23326205

44. Ren B, Wang X, Duan J, Ma J. Rhizobial tRNA-derived small RNAs are signal molecules regulating 
bioRxiv preprint doi: https://doi.org/10.1101/2021.11.09.467952; this version posted November 9,2021. The copyright holder for this preprint

(which was not certified by peer review) is the author/funder, who has granted bioRxiv a license to display the preprint in perpetuity. It is made available under aCC-BY-NC-ND 4.0 International license.

plant nodulation. Science (80- ). Science; 2019 Aug 30;365(6456):919-922.

https://pubmed.ncbi.nlm.nih.gov/31346137/ PMID: 31346137

45. Leinonen R, Sugawara H, Shumway M. The sequence read archive. Nucleic Acids Res. Nucleic Acids Res; 2011 Jan;39(SUPPL. 1). https://pubmed.ncbi.nlm.nih.gov/21062823/ PMID: 21062823

46. Neidhardt FC, Bloch PL, Smith DF. Culture medium for enterobacteria. J Bacteriol. J Bacteriol; 1974;119(3):736-747. https://pubmed.ncbi.nlm.nih.gov/4604283/ PMID: 4604283

47. Ayed Z, Cuvillier L, Dobhal G, Goreham R V. Electroporation of outer membrane vesicles derived from Pseudomonas aeruginosa with gold nanoparticles. SN Appl Sci 2019 112. Springer; 2019 Nov 12;1(12):1-9. https://link.springer.com/article/10.1007/s42452-019-1646-2

48. Zuker M. Mfold web server for nucleic acid folding and hybridization prediction. Nucleic Acids Res. 2003 Jul;31(13):3406-15. PMID: 12824337 
bioRxiv preprint doi: https://doi. org/10.1101/2021.11.09 467952. this version posted November 9,2021. The copyright holder for this preprint (which was not certified by peer review) is the author/funder, who has granted bioRxiv a license to display the preprint in perpetuity. It is made available under aCC-BY-NC-ND 4.0 International license.

A SRR2149893

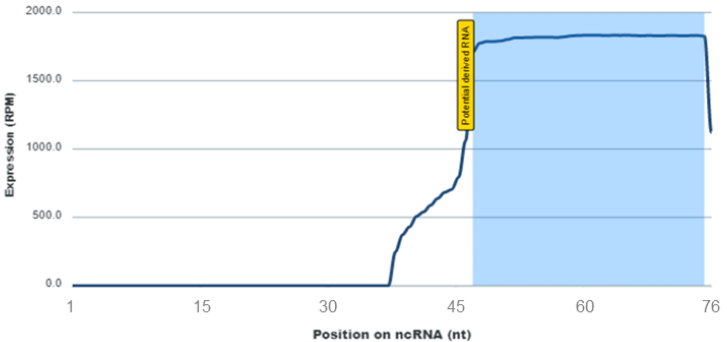

B tRNA-Thr-CGT-1-1, 44-73

5' AgGUCGUAGGUUCGACUCCUAUUAUCGGCA
C

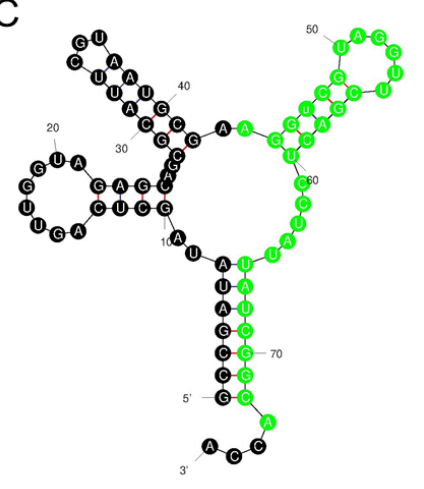

D

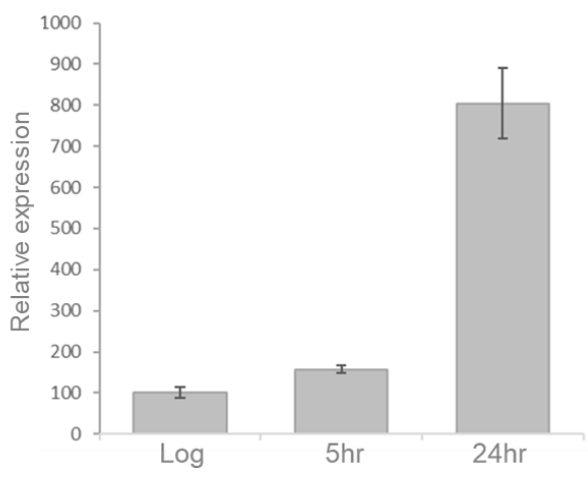

Figure 1. tRNA-Thr-CGT-1-1, 44-73. (A) SURFr ${ }^{30,31}$ "Differential Expression Vector" window depicting each nucleotide within tRNA-Thr-CGT-1-1 and indicating the fragment recurrently identified with a blue rectangle. The $x$-axis represents the position in the ncRNA selected (tRNA-Thr-CGT-1-1), and the $y$-axis depicts the expression level of the ncRNA at each position. (B) tRNA-Thr-CGT-1-1, 44-73 tRF sequence corresponding to the blue rectangle in "A". (C) Secondary structure of tRNA-Thr-CGT-1-1 with positions 44-73 highlighted in green. Structural prediction generated with $\mathrm{mFold}^{48}$. (D) qRT-PCR confirming the increased expression of tRNA-Thr-CGT-1-1, 44-73 tRF in S. Typhimurium during carbon starvation $(n=3)$. Relative expression, \% expression as compared to average Log expression. Log, logarithmic phase. $5 \mathrm{~h}, 5$ hour carbon starved. $24 \mathrm{~h}$, 24 hour carbon starved. 
A

tRf Thr-CGT 5'AgGTCGTAGGTTCGACTCCTATTATCGGCA

|| || ||| || || || || ||||||||||||

p22 phage 3'TCCAGCATCCAAGCTGAGGATAATAGCCGT

B

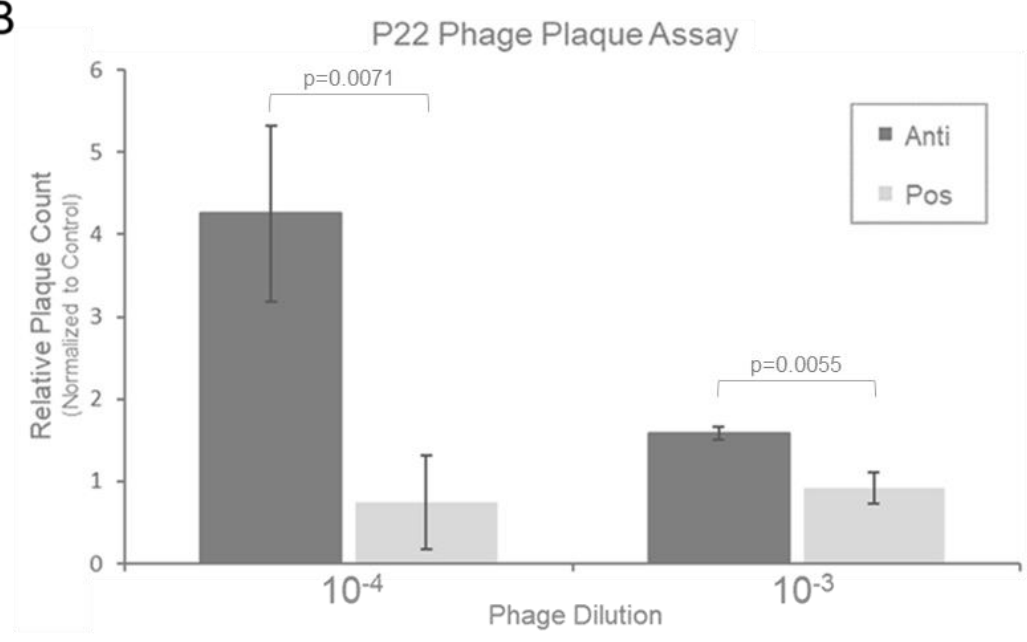

C

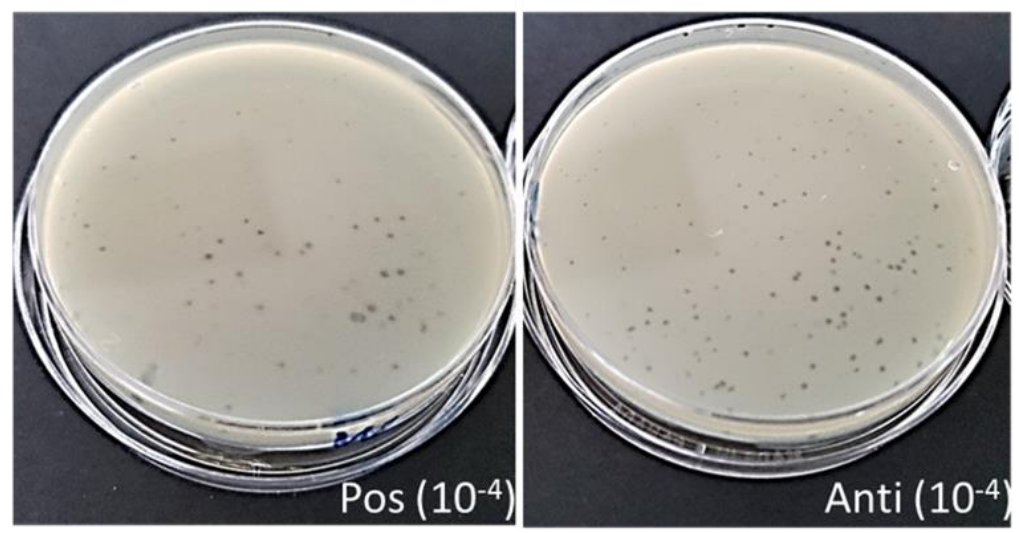

Figure 2. tRNA-Thr-CGT-1-1, 44-73 sequestration enhances P22 infectivity. (A) tRNA-Thr-CGT-1-1, 44-73 tRF alignment with P22 bacteriophage. (B) P22 plaque assay following preemptive transformation of $S$.

Typhimurium with an antagomiR oligonucleotide (Anti) designed to specifically bind and inhibit tRNA-Thr-CGT1-1, 44-73 tRF or its reverse complement (Pos). Plaque count was normalized to control: $S$. Typhimurium transfected with scrambled antagomiR oligonucleotide (Scram). Bacteria were transformed (CaCl2 heat shock) with antagomiR or control oligo and allowed to recover then viral lysate was added (at the indicated dilutions), mixed with molten top agar, and poured onto LB agar plates. Once solidified, plates were incubated at $37^{\circ} \mathrm{C}$ for $24 \mathrm{hrs}$ then plaques were enumerated. ( $n=3$, $p$-values determined by unpaired t-test). (C) Representative P22 $\left(10^{-4}\right.$ dilution) plaque assay. 
bioRxiv preprint doi: https://doi.org/10.1101/2021.11.09.467952; this version posted November 9, 2021. The copyright holder for this preprint (which was not certified by peer review) is the author/funder, who has granted bioRxiv a license to display the preprint in perpetuity. It is made

A

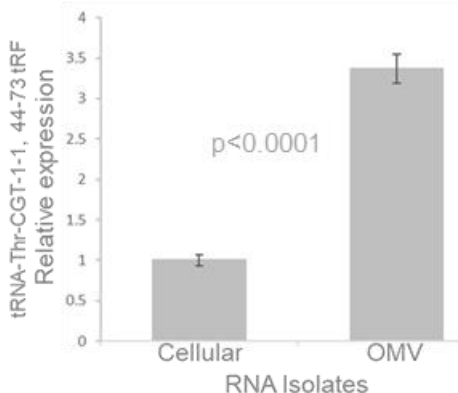

D

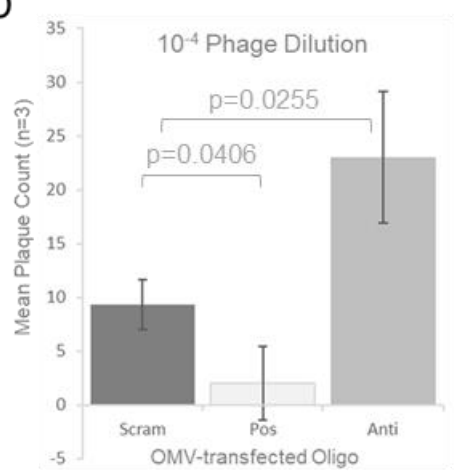

B

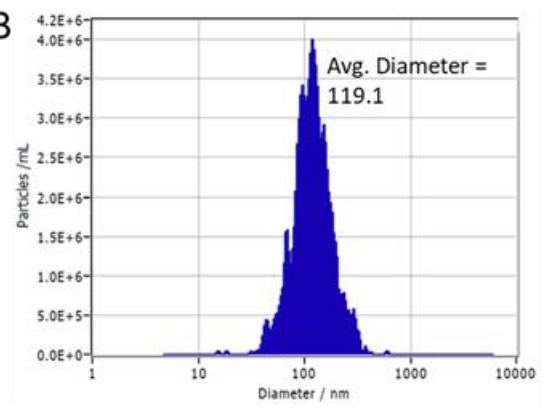

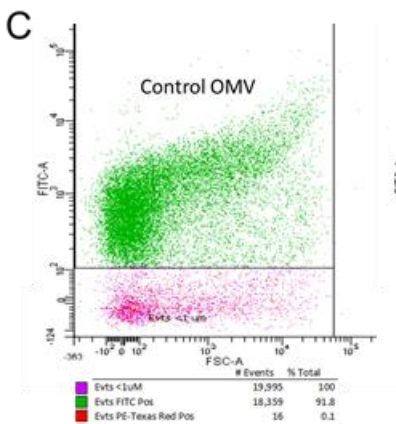

$\mathrm{F}$

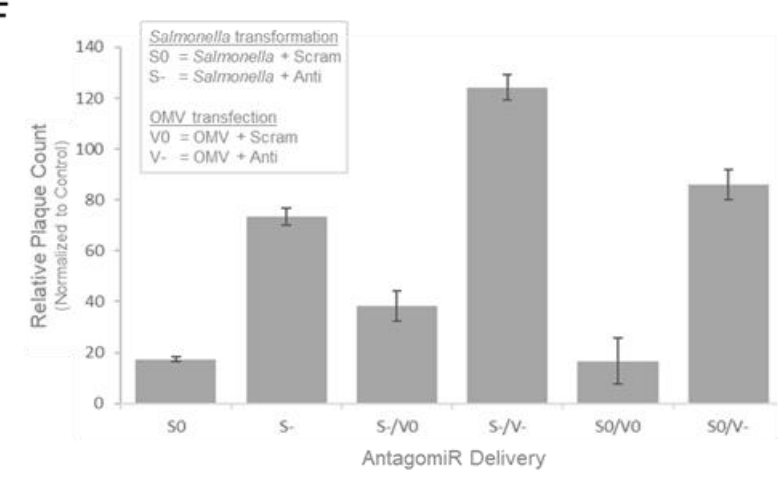

Figure 3. S. Typhimurium OMV inhibition of P22 requires tRNA-Thr-CGT-1-1, 44-73 tRF. (A) qRT-PCR confirming the expression of tRNA-Thr-CGT-1-1, 44-73 tRF in S. Typhimurium OMV RNA. Relative expression, $\%$ expression as compared to average total cellular RNA expression ( $n=3, p$-value determined by unpaired ttest). Cellular, total cellular RNA isolate. OMV, OMV RNA isolate. (B) $S$. Typhimurium OMVs were harvested then analyzed at a 1:100 dilution on ZetaView. Concentration: 1.3E8 particles / $\mathrm{mL}$. (C) $1 \times 10^{6} \mathrm{OMVs}$ from each sample were transfected with $1 \mu \mathrm{M}$ scrambled control oligo (left) or $1 \mu \mathrm{M}$ Texas Red labeled antagomiR (right) and stained using green fluorescent $\mathrm{DiOC}_{18}(3)$ membrane dye then analyzed by Aria FACS. Dot plots show fluorescent intensities of 20,000 events; maximal acquisition time was $6 \mathrm{sec}$ and sample pressure was $<2$. Percentages of gated populations are shown. (D) Plaque Assay (10 $10^{-4}$ dilution) following P22 phage preincubation with OMVs transfected with $1 \mu \mathrm{M}$ scrambled control (Scram), an antagomiR oligo designed to specifically bind and inhibit tRNA-Thr-CGT-1-1, 44-73 tRF (Anti), or its reverse complement (Pos). ( $n=3$, pvalue determined by unpaired t-test). (E) Plaque Assay (10-3 dilution), otherwise as in "D". (F) Plaque assay (10-4 dilution). "S0", S. Typhimurium transformed with Scram antagomiR control / no phage preincubation with OMVs. "S-", S. Typhimurium transformed with Anti antagomiR / no phage preincubation with OMVs. "S-/V0", S. Typhimurium transformed with Anti antagomiR / phage preincubated with OMVs transfected with Scram antagomiR control. "S-/V-", S. Typhimurium transformed with Anti antagomiR / phage preincubated with OMVs transfected with Anti antagomiR. "SO/VO", S. Typhimurium transformed with Scram antagomiR control / phage preincubated with OMVs transfected with Scram antagomiR control. "S0/V-", S. Typhimurium transformed with Scram antagomiR control / phage preincubated with OMVs transfected with Anti antagomiR. 
bioRxiv preprint doi: https://doi.org/10.1101/2021.11.09.467952; this version posted November 9,2021. The copyright holder for this preprint (which was not certified by peer review) is the author/funder, who has granted bioRxiv a license to display the preprint in perpetuity. It is made available under aCC-BY-NC-ND 4.0 International license.

Table 1. 31 tRFs expressed in S. Typhimurium SL1344. SURFr-identified tRF precursor positions and excised sequences are shown. OD 0.4, Mid-log phase. OD 2.0, Stationary-phase. SPI2, Salmonella pathogenicity island 2 conditions: $(\text { SPI-2 medium, OD600 }=0.3)^{28,29}$. OD 0.3, 24h and 5 h C-starved from ${ }^{27}$.

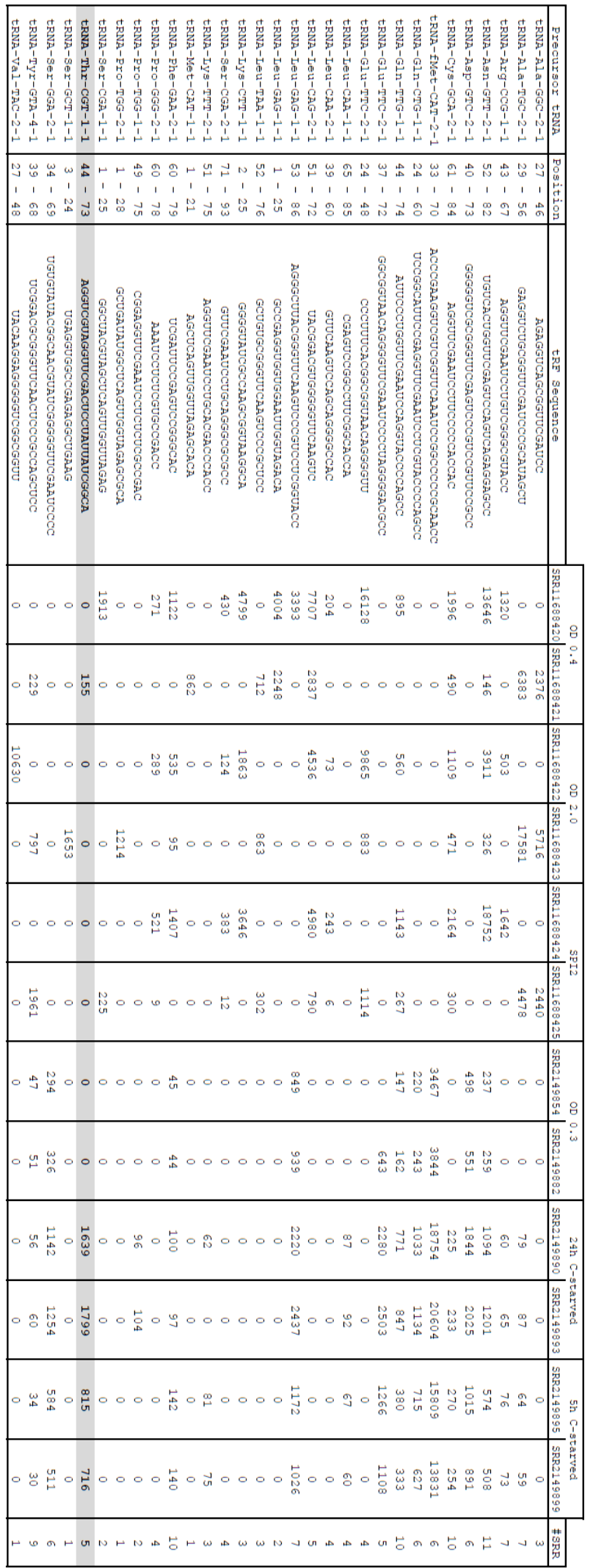

